\title{
FACTORS OF A PERFECT STRATEGY FOR RELATIONSHIPS IN ORGANIZATION - EXAMPLE OF EMOTIONAL ECONOMY
}

\author{
Miodrag Radivojević ${ }^{1}$, \\ Goran Biševac 2, *
}

${ }^{1}$ Intelligence and Reconnaissance Directorate of the General Staff of the Serbian Army ${ }^{2}$ Military Geographical Institute, Belgrade, Serbia
Correspondence:

Goran Biševac

e-mail:

sbakrac@yahoo.com

\begin{abstract}
:
The success of an organization depends not only on economic parameters. Relationships in organization represent social interaction and imply emotional reactions and various other forms of interpersonal relationships and form a very complex social field. The paper deals with the notion and phenomenon of emotional economy as a factor in successful management of relationships in the organization. The aim of the paper is to point out the importance of the influence of spiritual and emotional intelligence in interpersonal relations, as well as to present possible strategies for their management. Spiritual intelligence provides personal security and optimal effectiveness, building functional relationships among people, understanding and accepting change and resolving conflicts. Emotional intelligence is considered a key to business success. It is assumed that emotional and spiritual intelligence has a very significant impact on the creation of the competitive advantage of the organization, and that they are responsible for creating added value and building an organization's intellectual capabilities.
\end{abstract}

\section{Keywords:}

Organization, Economy, Management, relationships, emotional intelligence.

\section{INTRODUCTION}

Always human intelligence has been a great subject of interest. Our intellectual or rational intelligence is the intelligence we use in everyday life to solve the problem. Later, psychologists began to make tests for measuring this intelligence, and these tests turned into a means of assigning people to various degrees of intelligence, known as IQ's intelligence coefficient. The higher IQ's intelligence coefficient was considered by people to be more eloquent and this was a factor in determining human abilities.

At the end of the 20th century, scientist Daniel Goleman showed research by many psychologists and neurologists that emotional intelligence "EQ" is very important in human life in building and strengthening relationships and managing relationships in organizations, and in giving meaning and effective application rational intelligence IQ [1].

At the very end of the 20th and the beginning of the 21st century, scientists discovered that there is a third type of intelligence that is the third 
$\mathrm{Q}$, which is spiritual or spiritual intelligence "SQ". The full image of human intelligence is achieved by observing all three types of intelligence "Q", "EQ" and "SQ". Using spiritual or spiritual intelligence, we solve problems of value and meaning, it helps us to give a more meaningful and meaningful meaning to all life flows. Spiritual intelligence helps us to make effective use of "IQ" and "EQ", and "SQ" and this is the highest human intelligence stage for the time being.

There are scientists who claim that there are at least seven types of human intelligences, such as: spatial, musical, sports, emotional and rational [2], [3]. But other scientists argue that all these types of intelligence can be linked to one of the three neural systems in the brain, and hence can be classified into rational intelligence "IQ", emotional intelligence "EQ" and spiritual intelligence "SQ" [4]. Human intelligence has to be seen through these three contexts, because computers also have a visuku "IQ" because they know the rules and follow the procedures without error, and the animals have an "EQ" because they have a sense of the situation and know how to react [5]. However, none of them except the man asks for the meaning of all this, does not analyze the situation and does not ask if it can be any better [6].

The roots of human intelligence rest in our genetic code and in the entire evolutionary history of life on this planet. It is influenced by our everyday experience, our physical and mental health, the way of eating, the amount of physical exercise, the types of relationships we educate and many other factors [7]. However, neurologically speaking, everything concerning intelligence has been transmitted or controlled by the brain and its nerve sequences in the body.

\section{APPLYING EMOTIONAL INTELLIGENCE AND THE BENEFITS IT BRINGS}

Earlier, it was believed that when selecting candidates for admission to work positions in certain work organizations, care must be taken to ensure that applicants have as high IQ as well as a higher average during the studies. Even the limits have been set, for example, not receiving candinas from "IQ" below 150. However, this method of work has led to disastrous consequences for the work organization, since not all with the high "IQ" contributed to the organization, even became destructive. Practice has shown that at the present time, the most important thing is that the person has developed emotional intelligence "EQ" to become part of the collective, to fit into the collective and contribute to the organization. There are cases where employees with lesser knowledge and intellectual capacity surprised the quality of their work.

Nowadays, working organizations are managed by managers who need to keep this in mind when choosing a team of people to work with when they implement a relationship management and employee management strategy at their own company. The goal of each private work organization is to maximize profits, using all the potentials, knowledge and skills of employees, with the optimal use of time and means of work. In addition, every experienced and good manager knows that his goals in the organization will be achieved if his chosen team of people gives a personal example, human, moral virtue and quality. The manager will use the relationship management strategy, managing the skills of emotional intelligence: Self-awareness, self-control, adaptability, transparency, ensure that people maximally support themselves in their work, do their best so that the combined energy and work give the synergy necessary for the fulfillment of missions and the task of this organization, which is in most cases a profit. The use of an emotional economy and a relationship management strategy in an organization can be called an emotional economy. This example of emotional economy is applied in all democratic and economically developed countries of Western Europe and the United States.

Knowing emotional intelligence can contribute not only to a more humane approach to employees, but also to the new development of the concept of business, better results at work, a new understanding of leadership.

Emotional intelligence is not an ordinary kindness, constant smile and convalescence to the interlocutor. On the contrary, an emotionally intelligent man will often oppose wrong thinking and prejudice. EQ is not a free, uncontrolled manifestation of all of its emotions, but just the opposite. It means (successful) control of especially unhealthy emotions. Emotional intelligence strengthens and develops for a lifetime.

"EQ" emotional intelligence has been defined as "the ability to track and distinguish one's own and others' emotions and use that information as a guide for thinking and behavior" [8].

Domains of emotional intelligence and relevant characteristics:

Self - awareness [9]:

Emotional self-awareness: knowledge of one's own emotions and understanding of their actions.

Exact evaluation of oneself. 
Self-indulgence: a reasonable feeling of one's own values and abilities.

Rule itself [9]:

Emotional self-control: restraining turbulent feelings and impulses.

Transparency: Expressing honesty, integrity and reliability.

Flexibility: flexible adaptation to new situations or overcoming obstacles.

The pursuit of success. The urge to achieve personal standards of excellence through training.

Initiative: willingness to act and take advantage of the opportunity.

Optimism: a Positive View of the Event.

Social consciousness:

Empathy: Feeling the emotions of other people, understanding their perspective and expressing interest in their care.

Awareness of the organization: understanding of electricity, decision-making channels and policies at the organizational level.

Intelligibility: understanding and meeting the needs of employees, clients or customers.

Relationship menagament [9]:

Inspiring leadership: leadership and motivation based on an appealing vision.

Impact: skillful use of persuasion tactics.

Improvement of other people: encouraging their ability through guidance based on feedback.

Change catalyst: initiating, managing and operating in a new direction.

Conflict management: solving disputes.

Creating links: cultivating and maintaining a network of relationships.

Team work and cooperation: working together and creating teams.

Self - awareness:

Understanding their own emotions, advantages and disadvantages, the value of the motive is self-awareness.

Self-conscious people are above all realistic (not too critical or not even self-confident) towards themselves. Accurate self-assessment helps us to understand our possibilities and limitations. In this way, constructive criticism can be accepted and feedback can be given. When they know exactly the strengths and weaknesses, the foundation of security in their own personality is given. A clear understanding of one's own emotions, intentions - the possibility of managing one's own personality.

For leaders it is essential to restrain (understand) negative emotions that create a negative atmosphere and most directly affect the work of employees. Simply put, a leader can not effectively manage someone's emotions if he does not manage his own first. Emotional control does not mean denial and neglect of emotions and their choking. Leaders who possess emotional control manage to control emotional emotions and make them useful. Transparency refers to the fact that leaders live in accordance with their values.

Social consciousness:

Social awareness as a component of intelligence encompasses empathy, awareness of organization and sensitivity.

Empathy, the ability to feel compassion with others is one of the important aspects of "EQ". Paying attention to the feelings of employees, and then making the right decisions while taking care of others' feelings.

Social awareness is a component of the EQ and involves more awareness of the organization and the susceptibility of the leaders. Leaders, as a rule, have sharpened social awareness and political wisdom.

Relationship menagament [9]:

Relationship management is another feature of EQ. Leaders perform inspiringly, offering a sense of common purpose - which in fact goes beyond everyday tasks[10]. They affect people convincingly and attractively. They are able to instill others into self-improvement, consecutively and give feedback which makes them perfect mentors. A team friendly work creates a friendly and collegial atmosphere.

The skillful "management" of the conflicts is in the leader's ability to hear both sides and understand the attitudes and emotions of the involved actors of the conflict.

\section{EMOTIONAL ECONOMY}

In large companies around the world, management knows that human potential is the most valuable part of their intellectual capital. They are aware that "people are, above all, emotional beings, and then only reasonable." So the Emotional Economy "is an important segment of achieving the competitive advantage of each organization.

"The success of an enterprise does not depend primarily on how managers and owners understand economic 
principles or basic postulates of marketing, but also how much the owner is understood in the" emotional economy ". Each employer must understand how the development and goals of each employee are consistent with the goals of the organization, as well as to understand the correlation between each employee and the consumer.

Emotional economy as an asset that in today's business environment should provide greater employee commitment and greater loyalty to consumers, which will result in a better competitive position and greater profit, is followed by the Follow That Path by Curt Coffman and Gabriel Gonzalez Molina [11]. From the findings reached by the authors of the book, it is clear what the emotional economy is.

In the shortest, it is commitment to work, effective and efficient performance of the job using all its potentials. In this way, the added value of the company, as well as the relative capital, which also contains the elements of emotional intelligence of the employees, is created.

Coffman [11] considers that "the success of a company depends solely on how much the owner is understood in the" emotional economy ". Each employer must understand how the development and goals of each employee are in line with the goals of the organization, as well as to understand the correlation between each employee and consumer. "

"The Gallup Institute has compiled a performance system (Q12), which defines what individuals and businesses need to do to be successful and better than their competitors. This system of performance is the result of research of employee attitudes in relation to: employee fluctuation, productivity, employee satisfaction / dedication, security and profitability of the organization. Companies that manage to build a system that supports undetected twelve points as a result will have a better competitive position and, therefore, a greater profit.

"Q12 - the performance system includes the following 12 points:

Define the right results

Ensure the necessary funds

Select appropriate employees for the appropriate job

Focus on the strength of each employee

Care for employees

Identify the hidden talents of each employee and form teams based on that

Listen to employees, let them be heard

Help each employee understand the meaning of the mission
All employees together should provide quality to customers

Employees need each other to "keep their backs"

Employees like to know how advanced they are

Organizations learn through their employees."

For the successful implementation of the emotional economy, leaders, or managers, must be guided by the principles of the strategy of relationship management and emotional management. Like when the coach of a losing football team, hold a speech in the half-timing of his team, they return to their team after returning to the second half with a new idea of lead and win. What the coach used here, rather than managing the relationships and emotions of the soccer players, in this way ensured that they achieved their desired goal. The relationship management strategy implies 17 tactics that every leader must know and apply in his work:

- Be open and curious,

- Improve your natural style of communication,

- Avoid giving mixed signals in communication,

- Remember that small things can accomplish the goal (hit in the target),

- Welcome feedback,

- Build confidence,

- Implements an open door policy,

- It is only when you have a purpose for it (when you achieve a goal),

- Do not avoid inevitable,

- Recognize the feelings of others,

- Compliments of feelings or situations in which other persons are found,

- Show when you are worried,

- Do not just make decisions, explain them,

- Let your answer be direct and constructive,

- Synchronize your intent with your influence,

- When the negotiations fail, try to build relationships,

- Complete the difficult negotiations.

From all of the above it follows that the basic task of the company management would be to enable its employees to develop their potentials to the maximum and to use them at work. Leaders should be an emotional anchor in the organization and some kind of buckle in building the relational and human capital of the organization [11]. Coffman calls s In evolutionary contexts, Dickon's neurobiological work on language and 
symbolic representation shows that we have literally used SQ to develop our human brains. SQ has provided us with the necessary "installations" to become what we are and provide us with the potential for further "reinstallation" - for development and transformation, for the further evolution of our human potential. We use SQ to be creative. We call upon him when we need flexibility, visionary ability, or creative ability. We also use SQ in dealing with existential problems - problems when we feel that something has happened to us somewhere in life, that we are caught in a trap of habit or neurosis from the past, or problems associated with disease and depression. SQ makes us aware of the fact that we have existential problems and allows us to solve them - or at least to reconcile with them. It gives us a deep sense of the meaning of life's struggle.

SQ is our compass "on the edge". The most challenging living existential problems begin beyond the expected and well-known, beyond the established rules, beyond the reach of the previous experience, far from what we know to come to an end. In the chaos theory, the "edge" is the boundary between order and chaos, between the comfortable cognitions, which we strive for and total loss. This is a place where we can best express our creativity. SQ, our deep, intuitive sense of meaning and value, is our guide on the edge. SQ is our conscience. (In Hebrew, the words that signify "conscience", "compass" and "hidden, inner truth of the soul" have the same root).

We can apply SQ so that we become spiritually more intelligible in terms of religion. SQ leads us to the very heart of things, to unity that lies behind the difference, to the potential beyond any current expression. SQ can bring us in touch with the sense and essential spirit behind all major religions. A person who possesses a high SQ can exercise any religion, but without narrow eyes, exclusiveness, constancy or prejudice. Likewise, someone who is distinguished by a high SQ can possess distinctive spiritual qualities, without being religious at all.

SQ allows us to integrate intrapersonally and interpersonally, to overcome the gap between ourselves and others. Danijel Goleman (DanielGoleman) wrote about intrapersonal emotions, to those who inhabit within the self and interpersonal emotions - emotions that we share with others or use them in relationships with other people. However, a mere EQ can not help us overcome this gap. We need SQ so that we can understand who we are and what certain things mean to us, as well as how they give the other people and their meaning a place in our own world.
SQ is used in order to more fully oppose to the developed sizes whose potential we carry in ourselves. Each of us forms a character through a combination of experience and vision, through the tension between what we are currently doing and the larger, better things we can do. On a pure ego level, we are focused on ourselves, selfish, materially ambitious, etc. But despite this, we possess transpersonal visions of goodness, beauty, perfection, generosity, sacrifice, etc. SQ helps us overcome our immediate egoities and get out of them towards those deeper layers of potential that lie hidden within us. It helps us to live lives at a deeper level of meaning.

\section{CONCLUSIONS}

Collective SQ is low in modern society. We live in a spiritually defective culture characterized by materialism, the principle of usefulness, narrow-minded egocentricity, lack of sense and lack of commitment. However, as individuals we can work on the rise of our personal $\mathrm{SQ}$, moreover, further evolution of society depends on a sufficient number of individuals who will dedicate themselves to this goal. Generally speaking, we can increase our SQ by increasing the use of the tertiary process - our tendency to ask why, to seek for connections between things, to put the surface of the assumptions we create about the meaning behind inside the thing, to become more reflexive, to get a little out of ourselves, to take responsibility, to become more self-aware, to be more honest with ourselves, as well as to be more brave.

Through a more cultivated application of our spiritual intelligence, as well as through the personal sincerity and courage that such cultivation requires, we can reconnect ourselves with deeper sources and deeper meanings within ourselves, and this can be put into the service of objectives and processes that are much greater than us. In such a service we can find our psychic selfdevelopment. Our psychological self-development can rest in service to our own deep imagination.

\section{REFERENCES}

[1] D. Goleman, Emocionalna inteligencija. Geopolitika, 1997.

[2] H. Gardner, Frames of mind, Ingram publisher services US, 2011.

[3] H. Gardner, The theory of multiple intelligences. Ingram publisher services US, 2006.

[4] D. Zohar, Inteligencia espiritual. Plaza and Janes editores, S.A, 2001. 
[5] D. Zohar, Quantum society. HarperCollins publisher inc, 1995.

[6] D. Zohar, The Quantum Self: Human nature consciousness defined by the new physics. William Morrow paperbacks, reprint edition 1991.

[7] D. Zohar, J. Maršal, Duhovni kapital. Hesperia, Beograd, 2008.
[8] P. Salovey, J. D. Mayer, Emotional intelligence. Baywood publishing co. inc, 1990.

[9] T. Bradberry, J. Greaves, Emotional intelligence 2.0. TalentSmart, San Diego, US, 2009.

[10] M. Andevski, G. Nikić, Uvod u psihologiju menadžmenta. Cekom books 2012.

[11] C. Coffman, G. Gonzales-Molina, Follow this path. WARNER business books, 2002. 